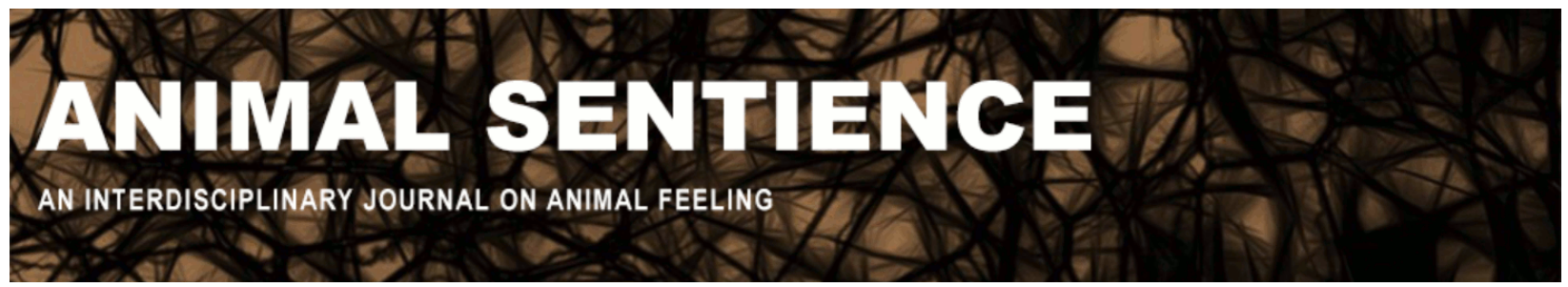

Cook, Peter F. (2017) Studying dog emotion beyond expression and without concern for feeling. Animal Sentience 14(15)

DOI: $10.51291 / 2377-7478.1282$

Date of submission: 2017-12-22

Date of acceptance: 2017-12-28

(c)

This article has appeared in the journal Animal

Sentience, a peer-reviewed journal on animal

cognition and feeling. It has been made open access,

free for all, by WellBeing International and deposited

in the WBI Studies Repository. For more information,

please contact

wbisr-info@wellbeingintl.org.

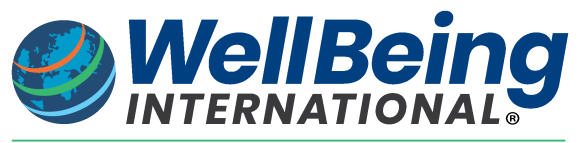

SOLUTIONS FOR PEOPLE, ANIMALS AND ENVIRONMENT 


\title{
Studying dog emotion beyond expression and without concern for feeling
}

Commentary on Kujala on Canine Emotions

\author{
Peter F. Cook \\ Department of Psychology \\ New College of Florida
}

\begin{abstract}
Studies of dog emotion have focused on the expression of social emotion, either because this is taken to suggest human-like feeling states in dogs or because it has been the most accessible signal of dog emotional processing. I argue for an approach grounded in affective neuroscience, relying on direct measures of physiology across different contexts. This work may be particularly fertile in exploring social emotion in the dog, not because dogs necessarily share human emotional states, but because they are unique in having likely evolved to fit a human social niche.
\end{abstract}
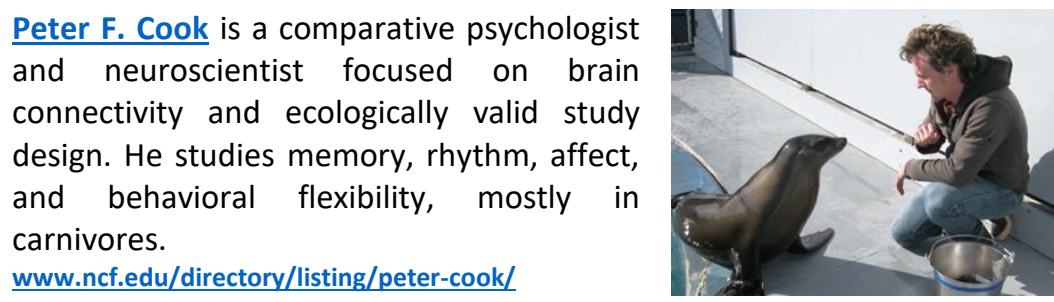

In an admirably thorough review, Kujala (2017) lays out the state of the science on social emotion in the domestic dog. Kujala uses the lens of human social psychology, but a more general review would have looked much the same. Research into social emotions dominates in affective canine science. Why?

Perhaps this is because our interest in how dogs feel stems from how we feel about dogs. Dogs elicit empathy, attachment, anger, and sorrow in large part because they express emotion in ways that humans find familiar and affecting. Because these expressions seem somehow human, and because they cause us to feel complex and very human emotions, it is all too easy to proceed with the assumption that dogs are in human-like emotional states. Some scientists seek to justify just such assumptions (Hare \& Tomasello, 2004; Adolphs, 2017; Morris, 2017). Others reject these views as anthropomorphic and suggest that our understanding of dog emotion should come primarily from observing expressions of emotion (Zentall, 2017; Harris, 2017; Martin, 2017). Because the expression is largely communicative, these researchers too tend to focus on social contexts.

Both of these frameworks that focus on human feeling and on dog expression have something to offer, but both are misguided in their approach to dog emotion. The expression framework correctly notes that empirical science cannot tell us how dogs feel. However, without recourse to anthropomorphism, science can tell us a great deal about how dogs process emotion beyond expression. In contrast, the feeling framework correctly notes that dog-human social interactions are potentially unique and worthy of research. However, this is not because 
emotional expression in dogs indicates that they feel what humans do. Instead, dogs present as a unique model for studying the effects of human social pressures on the evolution of emotion and its expression.

It is important here to distinguish between phenomenology and function. Feeling is a phenomenological state that entails consciousness. It feels like something to see the color red, but it is not yet clear what the physiological mechanisms in the eye and brain that allow vision have to do with this red feeling. I hold that emotion can be understood as a series of functional processes in the body and nervous system. As with perception or memory, these processes may often take place partly in conscious space, but it is not clear what consciousness contributes to them. Many researchers assume that conscious feeling is necessary for emotion, although they may disagree on whether consciousness is accessible to science. Kujala states, pragmatically, that even though we cannot know whether dogs have feeling states and thus emotion, we can still study relevant behavior and physiology. I believe this is correct, in practice. In principle, I disagree that consciousness is fundamental to the study of emotion.

Despite impressive efforts (LeDoux \& Brown, 2017), we cannot currently delineate particular mental states as either conscious or nonconscious without relying on subjective selfreport. But self-report is not a valid criterion, as made evident by its reliance on fallible memory (Pandit, Russel \& Wang, 2015) and its manifest limitations in split-brain patients (Gazzaniga, 2005). Because we do not have a functional account of consciousness, we cannot devise a biological explanation. Without a biological explanation, we cannot measure consciousness. Until we can, consideration of phenomenological feeling does not contribute to the empirical science of emotion.

Fortunately, affective neuroscience has advanced mightily without explicit reliance on identifying conscious mental states (Panksepp, 2004; Posner, Russell \& Peterson, 2005; Panksepp, Fuchs \& lacabucci, 2011; Damasio \& Carvalho, 2013). Researchers studying preference and motivation in humans and other animals have found that decision-making and learning are heavily influenced by valenced central representations of peripheral body states. These are collected and shared with frontal brain regions. The embodied representations are then used to influence decision-making, and play an integral role in learning and explicit memory (Damasio, Everitt \& Bishop, 1996). All studied mammals share these central representation and integration mechanisms (Condé et al., 1995; Craig, 2002; Naqvi \& Bechara, 2009), which can be understood in terms of information processing and adaptive behavior. Again, we have no such functional account for the role of consciousness.

Therefore, as scientists, we shouldn't ask whether dogs feel about us as we feel about them. Nor should we focus solely on the expression of emotion. Instead we should ask how dogs use valenced representations of peripheral body states to inform decision-making and learning, and in what situations these processes become engaged.

Such research is in its early days but has already demonstrated that dogs deploy emotion in a wide range of human social contexts. Neural reward systems are activated when dogs smell their owners (Berns, Brooks \& Spivak, 2015). Oxytocin is released when dogs lock eyes with a human (Nagasawa et al., 2015). Dogs in stressful situations show reduced cortisol after human interaction (Coppola, Grandin \& Enns, 2006). These results are informative but not necessarily surprising. Dogs evolved and have been bred to better fit into a human social niche, and human sociality has likely been a powerful shaping pressure on the species (Morey, 1994). Hence social 
pressures that have led in the human lineage to complex emotions like guilt, jealousy, and pride may also be acting on dogs. Careful comparative research will begin to address the extent to which social emotion in the dog has changed from that of its wild canid ancestors. Such evidence may cast light on the development and biological underpinnings of complex social emotions in humans.

From this standpoint, it is not dogs' ability to elicit fond feelings in humans but their unique evolutionary history in adapting to a human social niche that justifies the profusion of research into canine social emotion. However, the very pressures that may have driven dogs to develop nuanced social emotional processes could also act separately on the expression of emotion. Because humans are often the primary recipients of dog social signals, dogs' social behavior has likely been honed to appeal to human sensibilities. Scientists are only human, and we receive the signals dogs send us. We are prone to over-interpreting dogs' social capabilities. Note the profusion of papers making hay out of dogs' ability to follow human pointing (Hare, Call \& Tomasello, 1994; Soproni et al., 2002) despite the fact that sea lions, goats, and socially reared wolves can perform equally well (Kaminski et al., 2005; Udell et al., 2012; Arkwright et al., 2016). While humans reliably agree in interpretations of dog emotional expressions (Bloom \& Friedman, 2013), it is not yet clear in which cases these interpretations match the dog's internal state.

While emotional signals in dogs may not always be "honest" (see Pentland \& Hybeck, 2010), my collaborators and I have argued that physiological signals are more valid. We cannot know for certain what it's like to be a dog, but with careful measurement of internal states, we can make informed inferences (Berns, 2017). And it should be stressed that preliminary examinations of canine brain function support an interpretation of the dog as more than an opportunistic manipulator of human social tendencies (for reviews see: Berns \& Cook, 2016; Cook et al., 2016). We've shown that brain areas processing reward show equal or greater activation when dogs are expecting verbal praise compared to when they are expecting a hot dog (Cook et al., 2016). In combination with neuroendocrine evidence of social attachment in dogs, this suggests that dogs really do like us. But more work needs to be done examining physiological changes underlying gross behavioral signaling across a range of social contexts.

Dogs are accessible. They want to be with us. We're predisposed to respond to them socially. And they're increasingly finding their way into our science. They may have much to teach us about the emergence and expression of complex social emotions. But we should continue to build physiological accounts of dog emotion beyond behavioral expression. MRI, hormone analysis, peripheral physiological measures - all of these are increasingly affordable, available, and humane. We must also be careful and dispassionate in our analyses. We have not yet convincingly demonstrated the presence of social intelligence that so many of us have assumed in designing and interpreting our canine studies. 


\section{References}

Adolphs, R. (2017). Dogs consciously experience emotions: The question is, which?. Animal Sentience 14(2).

Arkwright, T., Malassis, R., Carter, T., \& Delfour, F. (2016). California Sea Lions (Zalophus californianus) can follow human finger points and glances. International Journal of Comparative Psychology, 29(1).

Berns, G. (2017). What it's like to be a dog: And other adventures in animal neuroscience. Basic.

Berns, G. S., \& Cook, P. F. (2016). Why did the dog walk into the MRI?. Current Directions in Psychological Science, 25(5), 363-369.

Berns, G. S., Brooks, A. M., \& Spivak, M. (2015). Scent of the familiar: An fMRI study of canine brain responses to familiar and unfamiliar human and dog odors. Behavioural Processes, 110, 37-46.

Bloom, T., \& Friedman, H. (2013). Classifying dogs' (Canis familiaris) facial expressions from photographs. Behavioural Processes, 96, 1-10.

Condé, F., Maire-lepoivre, E., Audinat, E., \& Crepel, F. (1995). Afferent connections of the medial frontal cortex of the rat. II. Cortical and subcortical afferents. Journal of Comparative Neurology, 352(4), 567-593.

Cook, P. F., Brooks, A., Spivak, M., \& Berns, G. S. (2016). Regional brain activations in awake unrestrained dogs. Journal of Veterinary Behavior: Clinical Applications and Research, 16, 104-112.

Cook, P. F., Prichard, A., Spivak, M., \& Berns, G. S. (2016). Awake canine fMRI predicts dogs' preference for praise vs food. Social Cognitive and Affective Neuroscience, 11(12), 18531862.

Coppola, C. L., Grandin, T., \& Enns, R. M. (2006). Human interaction and cortisol: Can human contact reduce stress for shelter dogs?. Physiology \& Behavior, 87(3), 537-541.

Craig, A. D. (2002). How do you feel? Interoception: The sense of the physiological condition of the body. Nature Reviews Neuroscience, 3(8), 655-666.

Damasio, A. R., Everitt, B. J., \& Bishop, D. (1996). The somatic marker hypothesis and the possible functions of the prefrontal cortex. Philosophical Transactions of the Royal Society B: Biological Sciences, 351(1346), 1413-1420.

Damasio, A., \& Carvalho, G. B. (2013). The nature of feelings: Evolutionary and neurobiological origins. Nature Reviews Neuroscience, 14(2), 143-152.

Gazzaniga, M. S. (2005). Forty-five years of split-brain research and still going strong. Nature Reviews Neuroscience, 6(8), 653-659.

Hare, B., \& Tomasello, M. (2005). Human-like social skills in dogs?. Trends in Cognitive Sciences, 9(9), 439-444.

Hare, B., Call, J., \& Tomasello, M. (1998). Communication of food location between human and dog (Canis familiaris). Evolution of Communication, 2(1), 137-159.

Harris, L. T. (2017). Do we understand what it means for dogs to experience emotion?. Animal Sentience 14(8).

Kaminski, J., Riedel, J., Call, J., \& Tomasello, M. (2005). Domestic goats, Capra hircus, follow gaze direction and use social cues in an object choice task. Animal Behaviour, 69(1), 11-18. 
Kujala, M. V. (2017). Canine emotions as seen through human social cognition. Animal Sentience 14(1).

LeDoux, J. E., \& Brown, R. (2017). A higher-order theory of emotional consciousness. Proceedings of the National Academy of Sciences, 201619316.

Martin, A. L. (2017). The development and expression of canine emotion. Animal Sentience 14(10).

Morey, D. F. (1994). The early evolution of the domestic dog. American Scientist, 82(4), 336-347. Morris, P. (2017). Direct perception of animal mind. Animal Sentience 14(5).

Nagasawa, M., Mitsui, S., En, S., Ohtani, N., Ohta, M., Sakuma, Y., Onaka, T., Mogi, K., \& Kikusui, T. (2015). Oxytocin-gaze positive loop and the coevolution of human-dog bonds. Science, 348(6232), 333-336.

Naqvi, N. H., \& Bechara, A. (2009). The hidden island of addiction: the insula. Trends in Neurosciences, 32(1), 56-67.

Pandit, J. J., Russell, I. F., \& Wang, M. (2015). Interpretations of responses using the isolated forearm technique in general anaesthesia: A debate. British Journal of Anaesthesia, 115(Suppl. 1), i32-i45.

Panksepp, J. (2004). Affective neuroscience: The foundations of human and animal emotions. Oxford University Press.

Panksepp, J., Fuchs, T., \& lacabucci, P. (2011). The basic neuroscience of emotional experiences in mammals: The case of subcortical FEAR circuitry and implications for clinical anxiety. Applied Animal Behavioral Science, 129, 1-17.

Pentland, A., \& Heibeck, T. (2010). Honest signals: How they shape our world. MIT Press.

Posner, J., Russell, J. A., \& Peterson, B. S. (2005). The circumplex model of affect: An integrative approach to affective neuroscience, cognitive development, and psychopathology.

Development and Psychopathology, 17(3), 715-734.

Sanders, C. R. (1993). Understanding dogs: Caretakers' attributions of mindedness in caninehuman relationships. Journal of Contemporary Ethnography, 22(2), 205-226.

Soproni, K., Miklósi, Á., Topál, J., \& Csányi, V. (2002). Dogs' (Canis familaris) responsiveness to human pointing gestures. Journal of Comparative Psychology, 116(1), 27.

Udell, M. A., Spencer, J. M., Dorey, N. R., \& Wynne, C. D. (2012). Human-socialized wolves follow diverse human gestures ... and they may not be alone. International Journal of Comparative Psychology, 25(2).

Zentall, T. R. (2017). The study of emotion in animals. Animal Sentience 14(3). 